This is an accepted version of a chapter published in Mobilities, mobility justice and social justice (2019).

This paper has been peer-reviewed but does not include the final publisher proofcorrections or pagination.

\title{
Mobility, Animals and the Virtue of Justice
}

Fredrik Karlsson

In this paper, I argue from a non-representationalist point-of-view that the capability of mobility - the practical freedom to move - serves to develop a virtue of justice. Also, I conclude that the scope of mobility justice is open-ended concerning the inclusion of nonhuman agents. Moving accumulates memories and adaptations of successful action in different material and social settings, thereby increasing the ability of agents to handle the complexity of environments. The components necessary for acts of justice - autonomy and intentional action - are consequences of being able increasingly to handle the complexity of the material world. This ability is not necessarily unique to human beings, and, therefore, nor are genuinely just acts.

Non-representational theory has its historical origins in early pragmatism, and acquired some inspiration from phenomenology. The world, it claims, consists of complex material relations that in part constitute phenomena that human beings experience as social, moral, spiritual and so on. There is nothing above and beyond materiality, although materiality is above and beyond strictly quantifiable parameters (Thrift, 2008, pp. 5-6). These relations are most obvious through shared experiences of the world that imbue language in an on-going, historical process. The mobility discourse I adhere to here is strongly influenced by nonrepresentationalist thinking, which views mobility as the main embodied thrust through which shared experiences of material resistance and agential possibilities are made. Through mobility we may be exposed to new places, technologies, species and people, and expand the relational network of which we are a part and, in turn, new opportunities for successful communication and common meaning-making (that may be oppressive) (Adey, 2017; McNay, 2004).

Associating mobility with the political-philosophical etiquette of 'capability' reflects such a material and relational stance, and situates mobility as a social justice concern. Amartya Sen (2001) developed the concept of capability in the 1970s to identify aspects of human flourishing, which involve the opportunity to exercise one's practical freedoms. Capabilities are actual opportunities that institutional arrangements (like infrastructure) make 
possible. They are also intrinsic to dignity; capabilities must be upheld in an equal manner for all to establish dignity and thereby social justice.

Aspects of Martha Nussbaum's view on capabilities are useful for non-representational theorizing. First, she (2006, p. 88) situates capabilities in a neo-Aristotelian framework, stressing "the animal and material underpinnings of human freedom", as well as people's natural reciprocity that extends beyond family ties. Second, she (2006, pp. 76-8, 159-60) argues that the rationale upon which society - and, thus, social justice - should be based, is driven by bodily needs (formalized into a list of capabilities), and uses Marx to argue that the purpose of capabilities is to make possible an "irreducible plurality of opportunities for life activity" (2006, p. 167). It is not hard to see that such agency also would demand the capability for mobility, although Nussbaum does not include it in her list of capabilities. Third, her close association of the issue of capabilities and social justice with materiality expands the notion of capabilities to include sentient, non-human animals. Because social justice is based on bodily needs that pertain to human and non-human animals, analogous lists of capabilities should be shaped for animals, and respected as a matter of social justice (2006, pp. 326, 392).

Calling mobility a capability, therefore, adheres to the view of mobility as an existential and benign condition of being in the relational complexity of the material world. It is a matter of social justice to acknowledge that mobility is necessary for beings to flourish (Bergmann \& Sager, 2008, p. 3; Kronlid, 2016; Merriman, 2012). That would also include non-human agents.

\section{Mobility Justice with Animals}

The mobility turn literature has begun to draw on social justice theory to frame uneven mobilities as a justice issue for human populations. This debate on social justice within the mobility discourse has reached a stage where it has become possible to prepare for, identify and/or promote sound normative guidelines. Familiar ethical approaches have appeared: the ideal is equal human worth, the object of critique is oppressive power relations and the solution is emancipation (Adey, 2017; Cresswell, 2010; Martens, 2012; Sager, 2018, p. 80-2). This explorative work also has increased our understanding of the significance of mobility as a capability (Kronlid, 2016).

Nevertheless, I follow up on other trains of non-representationalist thought, even if they are not all explicitly concerned with mobility. The reason is that the kind of normative work referred to above is concerned with problems (traffic, migration, etc.) involving human agents 
within political settings defined by human standards (realpolitik), which risks perpetuating the anthropocentric fallacy. Using this framework, at best we can, by analogy, adapt lists of human capabilities, or other anthropocentric norms, to other species (Nussbaum, 2006, p. 392401). However, as I have previously argued (Karlsson, 2012), such an approach typically reproduces anthropomorphic claims about the relatively low significance of other species. In contrast, Cary Wolfe (2010) and Nigel Thrift (2008) theorize agency and being as human and more-than-human phenomena. I draw on their and others' work to say something about the meaning of social justice when non-human agents are considered in a world of constantly flowing dynamics.

\section{The Stance on Ethical Theory}

An important domain of change that preoccupies non-representational theorists is perception, a term that is used to speak of materiality beyond data. Perception is vital in enabling humans to orient themselves in an ever-changing world. Conscious decisions about how to act are made pre-cognitively based on habitual perception, including affect (Thrift, 2008, ss. 6-7, 116-7). Thrift (2008, p. 179-87) argues that certain affects have become part of our biologies through evolutionary processes, but also that perceptive habits are shaped in, and often made coarse by, practices relying on cultural codes, political processes, media and technological advances. Agency is heavily influenced by perception, which is a kind of interactional intelligence that develops in social practice. Wolfe also uses perception to link individual agency with systemic processes. He (2010, p. 18-9) uses Niklas Luhmann's system theory to conclude that the environment, which harbors closed, self-sustaining systems (organisms), forcefully channels the agency of those systems to perceive meaning in the world. Therefore, he develops a close association between exercising agency and developing perception. As I will clarify in the analysis below, this relationship between agency and perception affects how moral agency and social justice in a more-than-human world are understood.

Within ethical theory, the ability to saliently perceive moral aspects of a particular situation is most often tacitly accepted as a necessity (how could anyone do right without perceiving what is wrong?). In some cases theorists reframe the issue of perception as one of empathy or other emotions (Donovan, 1996; Hume, 1998 [1751]; Noddings, 2003; Nussbaum, 2003, p. 19-88). Within a non-representationalist methodology, affect is indeed viewed as a significant expression of the relational processes involved in sentient beings' struggles to make sense of their environment. Perception, however, is not viewed as starting and ending with an empathetic individual. 
The work of Iris Murdoch and Simone Weil is useful in associating a nonrepresentationalist understanding of perception to ethical theory. This might be surprising as both are Platonists. Murdoch (2001, p. 33-49) suggests that moral perception involves sensing traces of transcended, objectively existing values, indirect clues that are experienced as beauty. Weil argues that attention relates to objective states such that attentive love emanates from God. Human beings, attempting to perceive the world through love, rely on the inclusion of attentive love in a theocentric, self-referential loop (Murdoch, 2001, p. 58, 82; Weil, 1972, p. 57). These insights are useful for non-representational theory because they do not limit moral perception to a human skill per se. Rather, it is a consequence of humility in the face of surrounding circumstances. Instead of aesthetic values or God, the non-representationalist would frame moral perception as a sense of awe produced from surmising the complexity of materiality. Therefore, an individual in and of itself does not and cannot know the meaning of morality or social justice. Only by trusting and refining a discerning perception can an individual handle ever more complex relational processes in a way that eventually leads to acts we call moral and just. This non-representational approach that foregrounds situational particularities rather than pre-formulated moral rules supports previous attempts to formulate an open-ended, unanthropomorphized and unanthropocentricized outlook on moral agency within ethical theory (e.g., Birch, 1993; Blum, 1991; Cheney \& Weston, 1999) by rendering their claims more substantial and empirically well-founded.

\section{The Stance on Social Justice}

In this stance on ethics, justice is conceived as a moral virtue, a character trait that enables a person to perceive as poignant the situational particularities that express (in)justice. This is the classical Aristotelian (Nichomachean) take on justice. Social justice, then, appears as a public good that regulates relations between people in a society in which conflicts may appear to result from a lack of resources and good intentions, or a disregard of the interests of others (Aristotle, 1993, p. 1129 a 26 - 1130 a 26). This notion of genuine justice is pluralist to a certain degree, but it largely presumes a regard for the interests of others of a kind, in which proportionality is central. Nichomachean ethics takes into account the perspective of many parties so that proportionality of relations between those parties can be achieved (Aristotle, 1993, p. 1129 a 26 - b 10).

The idea of proportionality as necessary to a formulation of justice outdates Aristotle (think of 'an eye for an eye'), and infuses contemporary theories of justice. For example, the expression to get what is one's due reflects how fundamental proportionality is to conceptions 
of justice. John Rawls's (1971) liberal theory of justice employs the maximin principle to offer an intricate algorithm of fair proportionality. Karl Marx's (2001 [1875]) justice principle of contributing according to ability and receiving according to need is rooted in the idea of proportionality. And Iris Marion Young's (1990) post-liberal call for justice as a lack of structural oppression for all social groups also maintains a commitment to proportionality. In all of these instances, creating harmonious and just relations in a society is seen to involve proportionality. Any notion of mobility justice, therefore, will benefit from a consideration of the relationship between proportionality and justice.

I use the concept of 'turbulence' to frame proportionality within mobility justice. Turbulence has been used within mobilities studies to theorize a mesophysical outlook on matter, the human condition and mobility. Cresswell and Martin (2012) suggest that turbulence is a kind of mobility that supports an (epistem-)ontology of uncertainty, chance and particular and unique instances. Even when the existential condition of mobility is situated in a world of turbulence, I suggest there is a place for justice. One of the main obstacles in understanding the parameters of justice in a turbulent world within moral philosophy is hegemonic representationalist interpretations of intentional action and the nature of autonomy. To bypass this problem in building a framework of mobility justice in a turbulent world, I outline the representationalist approach to intentional action, and then provide a non-representationalist alternative.

\section{The Representationalist Approach to Intentional Action}

Mobility, of course, involves moving from point A to B, but it also involves meaning-making, embodiment and experiences (Cresswell, 2010). For such terms to make sense, mobility must be distinguished from movements that are simply part of a line of causality, like the movement of asteroids and footballs. Movements that are not initiated by physical causes are the result of intention. Causality may be the reason you drop the china plate, but intention is the reason you pick up the pieces and glue them back together. Thus, autonomy, a will to alter the world at hand, is closely associated with intention. Intention and autonomy also are understood as criteria for moral acts; predestined or random acts cannot, by definition, be moral. There is no genuine social justice if causality is all there is.

Conventional, and typically anthropocentric, moral philosophy is allied with a representationalist outlook on autonomy and intention. According to the representationalist interpretation of the standard model of intentional action, such action is closely associated with practical reason (Stoutland, 2011). Intention is understood as a judgment attached to a 
possible action that is deemed desirable or good by particular terms (Davidson, 2002, p. 101). Judgments that are intentions are typically associated with wanting to have certain wants (for example, wanting to like sweets less). If such second-order volition is informed by practical reason, then we have an intentional action that, furthermore, is autonomous (to which moral responsibility is attached). While the criteria for intentional action include references to reason, and only human beings are believed to have reason, personhood has only been granted to human beings in this representationalist account (Frankfurt, 1971), meaning that only human beings may be included in the scope of justice. To avoid conceptually restricting intention to anthropocentric notions, I turn to a non-representationalist account of intention, which does not rely on a notion of practical reason.

\section{A Non-representationalist Approach to Intentional Action}

There is no reason to challenge the standard model of intentional action altogether. Human beings' intentional acts may very well be motivated by desires that are informed by beliefs, some of which are grounded in a better way than others. Rather than denying this, nonrepresentationalist theory provides other accounts of the meanings of 'beliefs', 'desires' and 'better', which do not limit intentional action to human agents.

Silberstein and Chemero (2011, p. 14; emphasis added), for example, claim that 'intention must not be merely causally prior to the action but must somehow correspond to the intentional structuring of action, without being something over and above the action'. While this non-representationalist understanding of intention mainly harmonizes with the standard model, it departs from it by conceiving intention as directly associated with material constellations. Cary Wolfe's intertextual reading of the linguistics of Jacques Derrida and Luhmann's system theory deconstructs intention by rejecting the idea of logical orders and, consequently, the idea that intention is associated with second-order volitions. Instead, he (2010, p. 31, 41-3) views intentional actions as a selection of all kinds of actions. There is no set hierarchy of action that positions certain wants as inherently more base or unreflective than others. Wolfe (2010, p. 45-7) locates intention in the tension between the being that wants and what is wanted. Consciousness (beliefs, desires) does not harbor intention as such, but language, as a mode of successful communication, does (Wolfe, 2010, p. 45-7, 56). By developing language, things are, literally, created (Wolfe, 2010, p. 60-1).

Silberstein and Chemero's (2011) non-representationalist account of intention is more concrete. They understand cognition as constituted by environmental components, as well as aspects of the cognizing individual body. Preferences and preferred objects are created 
through the intra-action of an information-processing body and its environment. For example, the pretense of eating broccoli not only co-creates the notion and manner of speaking of broccoli as edible, but also makes something like broccoli exist. Just as the fleshy leaves of the original Brassica oleraca invited the pretense to breed cultivars, the allegedly cancerfighting biochemistry of broccoli invites scientists to breed 'superbroccoli'. Intention is expressed through the relational aspect of this (quite long) process. They (2011) mainly refer to the microscale adaptations between animal and niche, by way of sensorimotor abilities and nervous system. Wolfe uses Luhmann to emphasize the evolutionary scale of this process, which is understood to include more than genetic processes. But they make a similar point. The preference to eat (something like) broccoli may be understood as the result of agricultural processing as much as an evolutionary co-creation of cognizing eater and environment. The notion of broccoli as edible is more fleeting than its actual edibility, but both notion and fact are co-created within the same dynamic system that includes agent and environment.

Silberstein and Chemero (2011) suggest that intentions are 'order parameters' that make a cognizing system act within certain constraints. The agency of the system is channeled by these constraints towards certain acts. For a mouse in a labyrinth, the walls and corridors, the smell of food at the exit and prior memories are among the order parameters that channel the mouse towards finding the way out. For more complicated acts, say parenting a child, social expectations, the needs of the child and parent, the extent and kind of communicative skills, the socio-economy and more shape each caring situation towards certain acts. The agency of the mouse or parent gains the honorary title of 'intentional' if it is restricted by the organism's attempt to make sense of its environment, to find meaning or to acquire a sense of value (Silberstein \& Chemero, 2011).

If a severely stressed mouse enters the labyrinth, then the lure of food might not be strong enough to 'order' the acts of the mouse, so it may remain passive or display stereotypies. The mouse would not be in a state of being that ables it to even attempt to find meaning in the situation; its behavior would not be intentional. Analogously, parenting may involve losing one's temper, at which point the usual attempts to find meaning in being a parent, make sense of the child's attempt to communicate or value the child are temporarily disrupted. Behavior on such occasions may be channeled by situational particularities (parameters), but it is not intentional.

There are, then, 'better' ways to behave. Performances imbued with successful modes of communication with meaningful consequences are better than others. This account of intention may offer an ethical foundation for non-representationalists, but it also renders 
unclear whether morality is merely a structural quality of the system or if the individual is implicated. In other words, autonomy is at stake.

\section{A Non-representationalist Account of Autonomy}

For the non-representationalist approach to intention to be ethically convincing, it needs to offer an account of why we would believe that individuals, at least occasionally, are responsible for their acts. Otherwise, individual and moral responsibility is in question, and with it the very idea of justice. Immanuel Kant understands autonomy as inseparable from practical reason. He (1914 [1788], p. 27, 31-2) acknowledges the ever-changing nature of matter, but uses the idea of practical reason to explain how people gain stable insights into what is 'right', and transcend the variability of their bodies, social relations and environment. This approach to autonomy structures the representationalist interpretation of the standard model of intentional action.

However, non-representational theorists eschew the concept of practical reason (Wolfe, 2010, p. xxv) in favor of the view that the sensation of intentionality is a human illusion, and acts are founded in pre-cognitive relational processes (Thrift, 2008, p. 6-9, 166). To replace the Kantian notion of autonomy, non-representationalists provide an account of beings' capacity to choose well as part of becoming in the world. For example, Niklas Luhmann's (1988) principle of openness from closure is central to Wolfe's (2010, p. xxi-xxv) outlook on autonomy. The autopoiesis of an organismal system closes such a system to itself, including the content of speech and cognition. If this closure were all there was, then the concept of autonomy would be no more than a majestic illusion veiling subjective prattle and predestined or random acts. It is assumed, however, that energy escapes the self-referential bubble. Any self-sustaining system is dependent on energy-input from its environment. The environment that harbors and provides energy to the organism offers overwhelming meaningfulness and material resistance, which must be handled by the organism, at the very least, to the extent of survival. This state of dependence encumbers the organism with adaptations and memories that create domains of information about the environment, which it shares with other organisms. Such domains are the foundation of communication (Wolfe, 2010, p. xxiv).

Individual organisms embody memories and adaptations of former intra-actions with certain aspects of the environment, and express them by communicative habits. As more environmental aspects are incorporated into the embodied self, the more complicated become the acts performed by the organism in that environment (Wolfe, 2010, p. xxi). Therefore, the appearance of the organism itself, seemingly independent from the environment, is a 
consequence of its dependence on, growth with and continuous intra-action with that environment. Autonomy accumulates with the complexity of the organism's intra-actions with its environment. Possibilities for autonomous action are temporary and conditional.

Silberstein and Chemero suggest that the complexity and non-causality necessary for achieving autonomy are reflected through the plasticity and robustness of the organism. Phenotypical plasticity means that genetically identical animals may develop disparate phenotypes due to differences in environment. Robustness entails certain traits of an organism persisting in spite of environmental and genetic variations. Both plasticity and robustness point toward the organism constituting a system in and of itself. Its resilience against certain genetic and environmental changes within certain limits admits a degree of individuality. This individuality grants the possibility of autonomy, which here refers to the ability to deploy various processes in order to uphold suitable relations in particular environmental circumstances. Such relations may be experienced as meaning and value (Silberstein $\&$ Chemero, 2011).

Just as the possibility for intentional action may be disrupted by changes in situational particularities, so can the autonomy of an organism. Responsibility for certain acts may be questionable in the non-representational view. But the moral agent is still obliged to intra-act, and is responsible for intra-acting in its environment, and for developing an ability to be autonomous, perceptive and considerate whenever such opportunities present themselves (Thrift, 2008, p. 285-7). Such an attitude gains meaning from the natureculture that is harboring the organism, which becomes proficient by accumulating embodied memories and adaptations of intra-actions with its environment. Having such an attitude is right because it readies the moral agent's capacity to make sense of the overwhelming meaningfulness of the environment, to discern values and to orient its actions according to such values.

\section{Turbulent Moral Agency}

The turbulence discourse questions the dichotomous relation between order and disorder, and between stasis and mobility. The robustness of an organism, for example, is upheld by myriads of chemical reactions in ever-flowing bodily fluids and intra-actions with habitats. Phenotypical plasticity rests on a capacity for morphological disorder, but becomes ordered through the organism's continuous attempts to handle environmental stress. Order and disorder are braided in ever-more complicated patterns until the autonomous body emerges in spite of being networked into environmental and genetical parameters. This process entails the 
labor of preparing the birth of morality thanks to the 'irreducible complexity in the order of events' in a world of turbulent matter (Webb, 2000).

The braiding of plasticity and robustness is analogous to Michel Serres's (2000, p. 27) example of turbulence; the flow of a river is ordered only because of the overwhelming force and complexity of many disordered flows. There are times when the moral vortex gets to swirl, and certain organisms become autonomous moral agents; those are times when situational particularities allow for moral agency to be exercised. At other times, material constellations forbid the very same organisms from exercising their moral agency. The turbulent nature of opportunities for autonomy means that whoever gains moral agency must be considered unknown until such agency actually appears.

\section{Concluding Discussion: Turbulent Justice in a More-than-human World}

Recollect, then, that mobility is existential and relational for any mobile agent, no matter their species, which may be conceptualized as a capability intrinsic to dignity that is owed such agents. Justice includes a notion of proportionality, and relies on the virtuous ability to perceive proportional and disproportional distribution of those goods we owe each other. A straightforward conclusion, of course, is that mobility justice would prescribe the proportionate distribution of the capability of mobility among the objects of justice. From the analysis above, however, mobility has a more complicated relation to justice than merely being a good to be distributed. As just acts presume moral agency, as the development of a body into an autonomous organism relies on adapting to the environment and as mobility expedites the ability to manage the complexity of the environment, mobility facilitates the development of the virtue of justice. The proportionate distribution of the capability of mobility, therefore, is necessary to affirm the turbulent nature of those beings that may gain from having such a capability, and allow them to develop into agents and even, perhaps, moral agents. The embodiment of moral agency and the capability of mobility are mutually supportive.

Such embodiment of moral agency is not necessarily limited to one species. Indeed, most primates refuse to cooperate when the reward is unequal to the acquired reward of a visible conspecific (Price \& Brosnan, 2012). Similarly, dogs refuse or hesitate to cooperate under conditions of unequal distribution (Horowitz, 2012; Range, Leitner \& Virányi, 2012). Ravens seem to uphold rules of food ownership through third-party ravens (not affected by the theft) that punish rule-breaking individuals (Heinrich, 2006, p. 269-79). Rats invest extra work in order to share a food source with conspecifics (Bartal, Decety \& Mason, 2011). The 
tendency towards this type of behavior varies not only between species, but also within species (Price \& Brosnan, 2012). To what extent terms like 'fairness' or 'justice' can be used to describe these behaviors is still debated (Brosnan \& de Waal, 2012; Christen \& Glock, 2012; Yamamoto \& Takimoto, 2012). The point, however, is that the representationalist habit of logically restricting intentional action and autonomy to human beings is presumptuous, and may belie empirical evidence. The question of who has moral agency is a matter of empirics, not logics, and non-representationalism offers apt openness to the concepts involved.

This ethological research demonstrates that a being apparently capable of intentional action and of perceiving proportionate and disproportionate distributive patterns may only concern herself when she is at a distributive disadvantage - apparently lacking altruism. Such behaviors are commonly observed, for example, among capuchin monkeys (Yamamoto \& Takimoto, 2012). Whether these observations are due to methodological limitations or actual behavioral limitations is unclear. Regardless, the adaptations made while struggling with the complexity of the environment must create some degree of altruism in order for recognizable social justice to appear.

The attention-oriented ethics outlined in the introduction of the paper offer an understanding of how a non-representationalist approach to intention and autonomy suggests the possibility of developing altruistic behaviors. Weil and Murdoch suggest that moral insights rest on percepts of transcendental values. Their approach to moral agency as fully dependent on the agent's protruding relations is similar to the non-representational outlook of moral agency. Instead of transcendental values, non-representational theory foregrounds adaptations of communicative habits or language. Instead of humility, it is more apt to speak of a willingness to communicate. Herein lies the potential development of altruism.

Communication only makes sense if there is an entity to communicate with. Such an entity must be perceived as being a communicable significant other. While communicative habits are the source of moral agency, the treating of a communicable entity as someone, rather than something, would be a necessary consequence of developing agency. As communication becomes more complicated, 'ideal role-taking' (Habermas, 1995) becomes more important. The agent's developing relation to the environment, including communicable entities, may reach a point where memories and adaptations have shaped communicative habits to the extent that the agent embodies some aspects of the reciprocity of another communicable someone and its environment. Agents' self-referential loops are linked by their common dependence on the environment, and close in on each other's life-worlds by perceiving the same world. The relational process between self-sustaining beings and the 
environment they are networked into may force on them the accumulation of communicative habits so complicated that role-taking becomes both possible and necessary. Many of the animal behaviors mentioned previously, like food-sharing, suggest that some degree of roletaking is common in other species than our own. From this insight on role-taking, we understand that those I communicate with share a somewhat similar situation in this world, and because we share this world commonly, they should be treated as I am. Proportionality in the division of labor, resources, punishment and merit may be expected within such communities.

Such an account of the development and unexpected appearance of intention and autonomy, which eventually conjoin with role-taking, has an important consequence for the scope of justice. It would be self-defeating to say that justice is owed only to those who have a sense of justice themselves. Rawls (1971, p. 505, 512) suggests such a rationale based on the idea that justice is premised on mutual advantage. In contrast, I argue that once the virtue of justice is acquired, and at those flickering moments when it can be integrated into behavior, that behavior necessarily adapts so that justice is done towards those that have something to gain from being treated justly. The scope of justice, then, would expand to include, at least, more animals than human beings.

What may be gained from being treated justly is unpredictable, so it is nonsense to include or exclude someone now based on the prospect that something may or may not happen in the future. Opportunities for mobility, however, should be granted proportionately and to an extent that respects the dignity of mobile agents. Some agents may then develop a sense of justice, but which ones cannot be known beforehand. Considering the development of moral agency, actual mobility has an instrumental value while it supports the development of social justice. Considering the scope of justice, however, the capability of mobility has an inherent value as an intrinsic part of the dignity of mobile agents. The reason why someone should be an object of justice is their dignity as agents. The problem of marginal cases that Nussbaum (2006) identifies in Rawls's theory - that the poor, disabled and non-human are excluded from the scope of justice - is avoided by this rationale. Even coma patients are included, as their ability to move again must be considered unpredictable. By virtue of the minimal chance that they regain consciousness, they are owed respect at least to the extent of being cared for. What matters for inclusion into the scope of justice is the unpredictably mobile nature of a being.

This insight provides yet another argument against the absurdly contradictory and surprisingly persistent notion that moral agency and a sense of justice justify the oppression of 
those less capable. Exactly who should be included in the scope of justice, however, cannot be logically concluded, because turbulent agency is an empirical matter. Nevertheless, I believe it is vitally important not to presume that sentience is a prerequisite for turbulent agency. Hopefully, with the rise of a non-representational ethics, we will also see the demise of sentientism, which has come to dominate animal ethics. Animals are worthy of respect by virtue of their (potentially mobile) existence, not because they can feel happy.

\section{References}

Adey, P. (2017). Mobility. New York: Routledge.

Aristotle. (1993). Den nichomachiska etiken. Göteborg: Daidalos.

Bartal, I., Decety, J., \& Mason, P. (2011). Empathy and pro-social behavior in rats. Science, 334(6061), 1427-1430.

Bergmann, S., \& Sager, T. (2008). Introduction. In S. Bergmann \& T. Sager (Eds.), The ethics of mobility: Rethinking place, exclusion, freedom and Environment (pp. 1-9). Abingdon: Taylor and Francis.

Birch, T. H. (1993). Moral considerability and universal consideration. Environmental Ethics, 15(4), 313-332.

Blum, L. (1991). Moral perception and particularity. Ethics, 101(4), 701-725.

Brosnan, S. F., \& de Waal, F. B. M. (2012). Fairness in animals: Where to from here? Social Justice Research, 25(3), 336-351.

Cheney, J., \& Weston, A. (1999). Environmental ethics as environmental etiquette. Environmental Ethics, 21(2), 115-134.

Christen, M., \& Glock, H. J. (2012). The (limited) space for justice in social animals. Social Justice Research, 25(3), 298-326.

Cresswell, T. (2010). Towards a politics of mobility. Environment \& Planning D: Society \& Space, 28(1), 17-31.

Cresswell, T., \& Martin, C. (2012). On turbulence: Entanglements of disorder and order on a Devon beach. Tijdschrift voor Economische en Sociale Geografie, 103(5), 516-529.

Davidson, D. (2002). Essays on actions and events. New York: Oxford University Press.

Donovan, J. (1996). Attention to suffering. Journal of Social Philosophy, 27(1), 81-102.

Frankfurt, H. G., 1971. Freedom of will and the concept of a person. Journal of Philosophy, 68(1), 5-20. 
Habermas, J. (1995). Reconciliation through the public use of reason: Remarks on John Rawls's Political Liberalism. The Journal of Philosophy, 92(3), 109-131.

Heinrich, B. (2006). Mind of the raven: Investigations and adventures with wolf-birds. New York: HarperCollins Publishers.

Horowitz, A. (2012). Fair is fine, but more is better: Limits to inequality aversion in the domestic dog. Social Justice Research, 25(2), 195-212.

Hume, D. (1998) [1751]. An enquiry concerning the principles of morals. Oxford: Clarendon Press.

Kant, I. (1914) [1788]. Immanuel Kants werke: Bd 5, kritik der praktischen vernunft, kritik der urteilskraft. Berlin: Cassirer.

Karlsson, F. (2012). Critical anthropomorphism and animal ethics. Journal of Agricultural \& Environmental Ethics, 25(5), 707-720.

Kronlid, D. (2016). Mobility as capability. In T. Cresswell \& T. P. Uteng (Eds.), Gendered mobilities: Towards a holistic understanding (pp. 15-34). New York: Routledge.

Luhmann, N. (1988). Closure and openness: On reality in the world of law. In G. Teubner (Ed.), Autopoietic law: A new approach to law and society (pp. 335-348). Berlin: Walter de Gruyter.

Martens, K. (2012). Justice in transport as justice in access: Applying Walzer's 'spheres of justice' to the transport sector. Transportation, 39(6), 1035-1053.

Marx, K. (2001) [1875]. Critique of the Gotha program. London: Electric Book Company.

McNay, L. (2004). Agency and experience: Gender as lived relation. The Sociological Review, 52(2), 175-90.

Merriman, P. (2012). Mobility, space and culture. New York: Routledge.

Murdoch, I. (2001). The sovereignty of good. London: Routledge.

Noddings, N. (2003). Caring: A feminine approach to ethics and moral education. Berkeley, CA: California University Press.

Nussbaum, M. C. (2006). Frontiers of justice: Disability, nationality, species membership. Cambridge, MA: Harvard University Press.

Nussbaum, M. C. (2003). Upheavals of thought: The intelligence of emotions. Cambridge: Cambridge University Press.

Price, S. A., \& Brosnan, S. F. (2012). To each according to his need? Variability in the responses to inequity in non-human primates. Social Justice Research, 25(2), 140-169. 
Range, F., Leitner, K., \& Virányi, Z. (2012). The influence of the relationship and motivation on inequity aversion in dogs. Social Justice Research, 25(2), 170-194.

Rawls, J. (1971). A theory of justice. Cambridge, MA: Harvard University Press.

Sager, A. (2018). Toward a cosmopolitan ethics of mobility: The migrant's-eye view of the world. Cham: Palgrave Macmillan.

Sen, A. (2001). Development as freedom. Oxford: Oxford University Press.

Serres, M. (2000). The birth of physics. Manchester: Clinamen Press.

Silberstein, M., \& Chemero, A. (2011). Dynamics, agency and intentional action. Humana.Mente, 15, 1-19.

Stoutland, F. (2011). Summary of Anscombe's intention. In A. Ford (Ed.), Essays on Anscombe's intention (pp. 23-32). Cambridge, MA: Harvard University Press.

Thrift, N. (2008). Non-representational theory: Space, politics, affect. New York: Routledge.

Webb, D. (2000). Introduction. In M. Serres (Ed.), The birth of physics (pp. vii-xx). Manchester: Clinamen.

Weil, S. (1972). Gravity and grace. London: Routledge and Kegan Paul.

Wolfe, C. (2010). What is posthumanism?. Minneapolis: University of Minnesota Press.

Yamamoto, S., \& Takimoto, A. (2012). Empathy and fairness: Psychological mechanisms for eliciting and maintaining prosociality and cooperation in primates. Social Justice Research, 25(3), 233-255.

Young, I. M. (1990). Justice and the politics of difference. Princeton: Princeton University Press. 